\title{
Prototyping Practices Supporting Interdisciplinary Collaboration in Digital Media Design for Museums
}

Marco Mason, School of Museum Studies, University of Leicester, Leicester, UK; Program in Science, Technology, and Society, Massachusetts Institute of Technology, Cambridge, MA, USA

\begin{abstract}
In the museum world, innovative design practices often result from collaborations spanning disciplinary borders within the museum. This article focuses on prototyping as one of the fundamental methods to support design activity, and to foster collaboration amongst members of the design team. In particular, the article aims to explore how prototypes support design practice by integrating knowledge coming from different team members' expertise. Using a qualitative research approach, this paper explores the use of prototypes in five digital media projects in museums. The qualitative data collected have been analysed and discussed through the lenses of the SocializationExternalization-Combination-Internalization (SECI) knowledge management framework. This study aims to contribute to a better understanding of how and why team members can take advantage of prototypes to create, transfer, combine, and embody knowledge.
\end{abstract}

\section{Introduction}

Designing digital media systems for museums is not only about designing the interactions for performing specific tasks but also about designing complex workflows, experiences, and interactions that weave together content, objects, information, visitor needs and expectations, in both physical and virtual space, while ensuring these fulfil the museum's mission and strategy. It is a interdisciplinary practice that often involves a large network of professionals, including directors, curators, educators, designers and developers (both internal and external), and sometimes other practitioners such as external advisers. This results in a situation where multiple voices with various backgrounds have to participate in the creative process in order to guarantee that different issues are considered in the design - from curatorial concerns to technical features. The final design solution should be the "best compromise", which satisfies all the 
stakeholders involved. This is primarily because designing for the visitor experience must address design problems which require the synthesis of multiple viewpoints and knowledge. Prototypes play a crucial role in these processes of knowledge creation. Lim, Stolterman, and Tenenberg (2008) conducted a comprehensive study of the nature of prototypes as manifestations and filters for design ideas in which they define prototypes as the "means by which designers organically and evolutionarily learn, discover, generate, and refine designs". Prototypes also support collaborative knowledge exchange between team members (Muller and Thoring 2011). A further advantage of prototyping at an early phase in the design process is the opportunity to "experience the design" (Warfel 2009), since a prototype goes further than just showing and telling, and as all team members can "play" with the prototype, thereby potentially increasing their understanding. Likewise, prototypes work as "learning vehicles" by which design progresses through repeated steps, each advancing its state (Wilkie 2010). As Cavillo et al (2010) state, despite its polyfunctional character, prototyping is essentially an act of the "production of knowledge."

The question this study aims to answer is: how do prototypes support digital design practice and help integrate knowledge derived from different team members' expertise?

There is a significant body of literature concerning explanation and categorization of prototypes (Houde and Hill 1997; Lim et al 2008; Patrie and Schneider 2007; Rogers, Sharp, and Preece 2015). However, a review of the literature has indicated a lack of research into how prototypes facilitate the creation and passage of knowledge to all team members and stakeholders, thereby facilitating the creation of a digital system that results in an organic integration of different fields of expertise, from curatorial to design to technical domains.

By using qualitative research, this paper explores the use of prototypes in five digital media projects. It aims to encourage theoretical reflections about how prototypes support collaborative design activities for digital media in museums by integrating knowledge from different team members' expertise. In this paper I will focus on relating the qualitative data to knowledge management theory: first by presenting seven 
analytical themes which emerged from the qualitative analysis, and then by discussing them through the lenses of a specific knowledge management theoretical framework.

\section{The theoretical Framework}

Nonaka's theory of knowledge management (Nonaka 1994; Nonaka \& Takeuchi 1995; Nonaka et. al. 2000; 2001a; Nonaka and Toyama 2003) offers a valuable analytical framework for investigating how knowledge is generated, transferred, and represented during the design of digital media in museums. Nonaka made a fundamental contribution to the theory of organizational knowledge creation with his 1995 book, co-authored with Takeuchi, The Knowledge-Creating Company, which explored the phenomenon of organizational knowledge creation (Laird 2004), considering knowledge creation as the source of continuous innovation for any organization. In particular, in this article I refer to the SECI model (1995)

(Figure 1). According to the authors' knowledge management framework, the process of knowledge creation moves from tacit knowledge to explicit knowledge and back. The tacit knowledge is personal and not always easily rendered visible and expressible (for example by a written document or a presentation), making it difficult to articulate and communicate to others. Hidden philosophies, beliefs, intuitions, and mental models belong to this category of knowledge (Polanyi 1967). Explicit knowledge can be transmitted in formal, systematic language (Polanyi 1967). It can be expressed in words, numbers, and images. This kind of knowledge can be more easily transmitted between individuals. Tacit knowledge tends to be available during a specific moment, while explicit knowledge is transferable at other times and in other contexts (Dubberly 2011). The two forms of knowledge are complementary and their interaction leads to the building of new knowledge. In order to describe how this interaction creates new knowledge, Nonaka hypothesizes four modes of knowledge conversion: Socialization, Externalization, Combination, and Internalization.

Socialization. Since tacit knowledge is difficult to formalize and is often context-specific, it can only be acquired by sharing the same experience through joint activities. For example, a designer might acquire 
tacit knowledge from a curator by showing and using a prototype during a meeting. The prototype facilitates the sharing of tacit knowledge thanks to its intermediation between the designer and curator. The new tacit knowledge acquired by the designer is useful to further advance the design of the interface.

Externalization (from tacit to explicit) consists in articulating tacit knowledge by transforming the tacit knowledge into something more explicit. According to Nonaka (Nonaka, Konno, and Toyama 2011) "through externalization, tacit knowledge is expressed and translated into such forms as metaphors, concepts, hypothesis, diagrams, models, or prototypes so that it can be understood by others." This transformation makes knowledge sharable with other people involved in the project, and promotes reflection and interaction between team members.

Combination (from explicit to explicit) leads to the creation of new knowledge by the reconfiguration of existing (explicit) knowledge through adding, combining, integrating, and categorising. This process aims to model a better situation; for example, by building a prototype that combines knowledge coming from different team members' expertise. As a new form of externalised knowledge, the prototype can be presented and distributed among team members.

Internalization (from explicit to tacit) allows individuals to embody knowledge by learning and acquiring new tacit knowledge in practice. This happens by "learning by doing" or by sharing, for example, documents, mental models, and prototypes (Nonaka and Takeuchi 1995).

\section{The Study Context and Research Approach}

\section{Study Context and Case studies}

This article on prototyping is part of a larger study funded by the European Union, which I am presently carrying out as Marie Curie fellow - International Outgoing Fellowships (IOFs). The purpose of this ongoing project is to investigate the phenomenon of digital media design in the museum context by 
analysing and interpreting existing design practices. Prototyping as an essential practice in collaborative design for digital media in museums is one of the core themes emerging from the study.

The five digital media projects which are the subject of this article were selected as case studies after a review of the current literature and attending international conferences. The case studies selected each adopted a human-centered design approach and undertook an intensive collaborative design process. I met personally with the project leaders of each case study before I started gathering data, in order to verify that the project met the selection criteria. The following is a brief description of each project (further information is available in Appendix A).

The Emerging Issues Commons at the Institute for Emerging Issues, NC State University, USA

The gallery comprises digital interactives and physical components through which visitors can explore statistical data-driven interactives, the personal stories of prominent North Carolina figures, and relevant social media (Figure 2). The exhibition was the result of more than two years collaborative effort between the Institute, a digital design studio, a museum planning and design firm, and a marketing agency.

"Native American Voices: The People-Here and Now" at the University of Pennsylvania Museum of Archaeology and Anthropology, Philadelphia, PA, USA

In this exhibition (Figure 3) "visitors can see over 200 objects from its expansive North American Collections. The exhibition challenges common Native American stereotypes and explores the many ways in which today's Native leaders are creating and maintaining religious, political, linguistic, and artistic independence. [...] Through old and new objects, video and audio recordings, and digital interactive opportunities, this exhibition allows visitors to develop a new understanding of the original inhabitants of this land, as told through Native American voices" (2014). The four interactive media towers, twelve touchscreens, and a motion-activated central projection are the result of one year of collaborative effort between the museum team and a design studio. 


\section{Tenement Museum's "Shop Life" in New York city USA}

Through the exhibit visitors explore the immigrant businesses where neighbourhood communities worked, shopped, celebrated and struggled for more than a century ${ }^{1}$. The digital interactive system consists of a 24-foot counter capable of hosting fifteen visitors (Figure 4). The interactive enriches the objects on display with digital content that tells the stories of the shops that once sold the products that are now part of the museum collection. The Tenement Museum team closely collaborated on content creation and concept development with a design firm considered to be experts in interaction design and digital technology development.

The Behind the Scenes galleries at the Museum of Fine Arts in Boston, MA, USA

The galleries (Figure 5) are constituted of four interconnected, interactive galleries, offering a multilayered approach for the interpretation of art through an integrated system of digital interactives. The digital system provides visitors with a look at how the Museum and its curators collect, classify, and care for the works in the MFA's Art of the Americas collections, and how certain choices are made about what objects to put on view. The final design is the result of an organic collaboration between the museum team and external design firms throughout the entire process.

Gallery One at the Cleveland Museum of Art, OH, USA

Gallery One (Figure 6) is an art gallery that provides visitors with a rich interactive environment constituted by digital interactives, a large multi-touch wall, and a mobile app. There are six interactive "lenses", each comprising a touch screen that interprets groups of related artworks. The lenses consist "of a unified framework upon which a variety of interactive multimedia, games, and vignettes were built. All six lenses share a similar home screen layout, framing the artworks in front of the lens." (Alexander, Barton and

\footnotetext{
${ }^{1}$ http://www.tenement.org/shoplife.html
} 
Goeser 2013). The Collection Wall offers visitors an experience where they can explore and browse a variety of digital content related to artworks displayed in the museum gallery and then can transfer information to an iPad app.

\section{The research methodology}

Grounded theory is the one of the methodologies best suited to generating theories of social process (Glaser and Strauss 1967), where there is clear interest on the analysis of processes (Punch 2013). For this reason, Grounded Theory has been used to study multidisciplinary design processes in several design disciplines (Jagodzinski et al. 2000; Lee and Cassidy 2007; Le Dantec and Do, 2009; Geber and Carroll 2011).

Data was gathered from multiple sources: fifty-nine interviews with team members with both museums and external design firms (appendix B); the collection of team-generated materials (e.g. documents, submissions, prototypes, etc.); communications and files stored in Basecamp (for two case studies); conference proceedings in which the museums wrote about the projects (appendix A); videos of conference presentations in which the projects were described (appendix A); a two day workshop ${ }^{2}$ organized by the Cleveland Museum of Art during which they presented several sessions to describe different aspects of the Gallery One project. I also interviewed an external design consultant ${ }^{3}$, who has been offering support for design strategy in the museum setting (using several different prototyping techniques). Materials were collected over eighteen months, during which I cyclically iterated the data collection and analysis, as expected in grounded theory methodology. The entire research activity related to the data gathering (e.g.

\footnotetext{
${ }^{2}$ http://www.museumsandtheweb.com/cma2013/

${ }^{3}$ I am grateful to Dana Mitroff Silvers for the stimulating conversations on design issues.
} 
interviews) was subject to approval by a committee ${ }^{4}$ on the use of humans as experimental subjects. To obtain informed consent from interviewees (appendix C), I provided the participants with a detailed explanation of the research, its purposes and procedures, as well as the participant's rights regarding anonymity, confidentiality, and withdrawal from the study.

The interviews were based on a qualitative research protocol that allowed participants to describe what things were significant for them during the design process (Kvale 2008). I adopted an in-depth interview approach with open-ended questions. In particular, I choose an "Interview Guide" format (Patton 1990), which was based on a common outline of issues: interviewees roles in the project, activities conducted, artifacts produced, activity and relationships with other members with and outside their teams, and design processes. I made large use of whiteboards during the interview sessions. The advantage of this interview strategy was to facilitate interviewees' descriptions of their work (design activities are often tangled, so visualizing relationships and tracing connections can be of great support); stimulate the conversation (designers are "visual people" who feel comfortable "speaking" with a marker in their hand); by using a visual aid, relationships between things emerge more clearly (e.g. collaboration with other members) than with only a verbal description. Each interview lasted an average of one hour. The interview sessions were audio recorded and transcribed ${ }^{5}$.

\footnotetext{
${ }^{4}$ MIT policy require that the Committee on the Use of Humans as Experimental Subjects (COUHES) review and approve all research involving human subjects that is performed under the auspices of MIT. The COUHES operates in respect of Federal mandate (The Common Rule 45 CFR 46). I completed and passed the appropriate human subject training course before the research protocol was approved.

${ }^{5}$ The interviews of the first case study were almost all video recorded in order to make the best of the whiteboard strategy. I decide to adopt this very time consuming technique (in term of transcription and analysis) only for the first case study, as the initial phase of ground theory research is crucial because it creates the basis for further data gathering and successive analysis. For the later case studies it was more than sufficient to record the interviewees and take pictures of what written and drawn on the white board. When recording was not possible due to ethical restrictions, extensive notes were taken.
} 
The data gathered were then analysed and interpreted, and constantly compared with the data about artefacts used in the process (Glaser 1978). I used a piece of computer-assisted qualitative data analysis software named NVivo 10 (Bazeley and Jackson, 2013), which supported the work of managing and analyzing the data. I started the analysis using an "open coding" approach that consisted of reading through the transcriptions, line-by-line, in order to break down each interview into segments. In doing this first analysis, I assigned a label to each segment. The label consisted of a few words that briefly described the essential property of the segment ${ }^{6}$. In the phase of "selective coding", seven core analytical themes were refined and selected.

\section{Findings: Analytical Themes}

This section of the article presents seven analytical themes that describe how prototyping takes part in the processes of creation, transition, and sharing of knowledge within multidisciplinary teams for digital media design in a museum context. Extracts from the interviews illustrate each category.

\section{Prototypes as a representation of how the design "is going to work"}

For the Native American Voices: The People-Here and Now project at the Penn Museum, the museum team worked closely with the digital design team on a prototype for both designing the information architecture and creating digital content for a multi-touch kiosk (Figure 7). The following extracts will describe how the wireframe (Figure 8) helped the content development team at the Penn Museum to understand the interface structure and its interactions.

\footnotetext{
${ }^{6}$ During this process of labelling, patterns of similar properties started emerging. They were functional in creating emerging conceptual categories that, during the "axial coding", I organized hierarchically and the relationships of which I started. I constantly wrote memos each time significant reflections emerged from the analysis, which helped to make conceptual leaps from the raw data to emerging themes (Birks et al. 2008). At the same time, I researched appropriate literature (which is in large part reported in this paper) to understand existing theory, progress the analysis, and explain the diverse ideas which were emerging (Dunne 2011).
} 
Lead Designer at Penn: "But what they're doing is thinking of them as isolated. And so my team's thinking of, I'm going to count all of these photos and I'm going to write all these labels and I'm going to do this. But no one seemed to be thinking about how it was going to work.

[...] And so [the external designer] is just like, well, where is all this content going? So we had this framework in place [the interactive wireframe]. [...] And trying to get them to understand the functionality of the interactivity as you're writing it and as you're building this information."

[...] I was like, this is what it's going to be. This is how the interactive is working. [...] This is the functionality, because we had a basic understanding of how I thought it would function. [...] And that really wowed them and they were like, wow that's going to be amazing. Right. This is why we need to do this"

The extracts refer to the initial phase of the design, which followed the conceptual phase. At this point, the museum team, together with the digital media firm, had already defined the overarching exhibition concept. In order to advance the design, the team had to face the problem of how all the content could fit in the digital media in terms of structure, form, and interaction. The digital media designers put their knowledge at the disposal of the content team by first defining, and then showing how to structure, digital information. By understanding how the system worked, the content team could produce digital information in a way that best suited the interactive experience. They were the content experts and the success of the digital system strongly depended on their contribution; in other words, their knowledge.

In the extracts the Lead Designer at Penn Museum stresses the importance of the content team in understanding how the system would work. Initially, the content team worked in isolation, producing material without taking into consideration how visitors would experience it through the interactive digital interface. The set of wireframes was essential to allow the content developers to understand how the digital interactive was going to work in order to build content according to the functionality of the interactive.

In this example the prototype worked as a shared representation of the design (Johansson and Arvola 2007) supporting collaborative work between content developers, curators, and digital designers. The 
understanding of the system's interactions, its internal structure, and the configuration of the layout was more than sufficient to allow the content developers to contribute their knowledge to the design. The prototype was an externalisation of the design that worked as a common language, facilitating the sharing of knowledge between interaction designers (knowledge about interface structure and interaction) and content developers (knowledge about how to create meaningful information).

\section{Prototyping for transferring and sharing team members' knowledge}

Thanks to their ability to "externalise", prototypes can work as a vehicle to transfer knowledge. The following example comes again from the Native American Voices: The People-Here and Now project. This time the problem the museum and digital teams faced was how to make the layout of the multi-touch kiosks and interactive towers (Figure 9) look a "little less traditional" and, at the same time, create visual consistency between the interactives and the exhibition. This section describes how prototypes support the integration of content, graphic design, interface design, and software development expertise. Besides different forms of expertise (from the project manager, to curators to content experts), the museum team could count on a designer who was in charge of the graphic design for the exhibition. In the following extract the designer explains the genesis of the graphic:

Graphic designer at Penn Museum: "So, we basically first look at our collections, and all the objects, and all the icons from the Native American objects. So, we found out that the elements can visually make the whole graphic look contemporary and in a very dynamic shape, because both can be put together in a very fresh way, but you still feel that these have a very deep connection with the Native American people."

During the design process the graphic designer produced several prototypes of the logo (Figure 10). Similarly to what was discussed in the previous sessions, these prototypes worked as "externalizations" supporting the conversation between the graphic designer and the exhibit curator, who ensured the graphic 
respected the meaning of the collection while also taking into consideration external feedback from the Native American advisers ${ }^{7}$.

Graphic designer: "So I showed to [the exhibition curator] that the objects have all these geometric shapes and so how the graphic can tie the image together. I presented how the logo looks, so she understood so fast $[\ldots]$ "

And here is an extract from the interview with the exhibition curator:

Exhibition curator at Penn: "She's very talented, I think. At one meeting, she just pulled forward her images [i.e. prototypes] and there were several different ones. [...] She retained the sense of color. For Native people, there's always a directional association with color."

For my argument it is significant to note that the graphic designer at the Penn Museum also:

“[...] was already thinking that maybe I could use icons for the interactive too, and that I could use a lot of buttons on the touch screens. I believe when we discussed the design in the early stage, we partly had taken the interactive into part of the consideration already."

In parallel to the logo design process, the interaction designer - a member of the external digital media team - was working on the layout for the interactives, struggling to find an effective design solution to articulate the content provided by the content development team at the Penn Museum. She produced initial wireframes to define the grid at the base of the interface structure. She also used the wireframe to work collaboratively with the developer, who wrote some coding to prototype and test the layout interaction and movement in order to understand feasibility issues. The interaction designer produced a:

7 Native American Voices: The People - Here and Now was developed in collaboration with numerous Native American advisors and contributors who graciously allowed the Penn Museum to present their opinions and works: http://www.penn.museum/sites/nativeamericanvoices/contributors.php\#navadv 
"solution that I was thinking was like a grid of images [...] So I did just a wireframe that graded out boxes, because there was like a set number of everything; there's thirteen bios, seven audio essays, forty audio videos. We needed to figure out how to make those all fit, but also move. [...] So that is when I kind of like worked with the developer, back and forth with grid size. [...] But, then, how to make it look a little less traditional?"

It is here where the logo prototype helps the digital team to find a solution to this graphic issue.

Interaction designer: "[The graphic] designer came up with this logo that was just geometric shapes and was really early on [...] that's kind of when we came in. And then from there I just took that geometric shape and incorporated that into the towers."

In this example, the ability of prototypes to externalize knowledge faciliated the transmission of knowledge amongst team members. The prototypes were literally "vehicles" for knowledge sharing (Wilkie 2010). Initially, the collection inspired the design of the logo, then the graphic prototypes were the medium to share knowledge with the exhibition curator, and, even further, with the Native American advisers; and finally, the prototype transferred knowledge to the interaction designer. In the same way, the wireframes fulfilled a similar function for the layout as it transferred knowledge between interaction designer and developer (as described in the previous session), between interaction design and content team. The prototypes work as a medium to support the dynamic migration of knowledge.

\section{Retaining information}

Knowledge transfer does not only occur in circumscribed situations, but also across the entire design process over longer periods of time. For instance, a developer could (re) enter the project during the development or even in the implementation phases, when the design has been already defined. She needs to understand the visitor experience, interactions, and user interface decisions already taken in order to best employ her knowledge to build the software. The following extract from "The Emerging Issues Commons" projects describes a similar scenario: 
Senior developer: "[The documents and prototypes produced] are very important for me. [...] After that prototype, I pretty much went completely off the project. We brought another big project into the studio and I was very focused on that for a long time. By the time I was able to disentangle myself from that, a lot of this stuff that you're seeing here, these conceptual documents, had already been very fleshed out. It was time to start building it already. [...] I had a period where I had to understand all of this stuff. I went through these documents [including prototypes] that we had gone back and forth with the client on. I had to go through all of that and then I had to plan out well, how are we going to build the back-end in that supports all of this stuff?"

The example shows that it is important to retain knowledge produced and place it at the disposal of team members during the entire project, especially for long processes that last one or two years. In this way, the knowledge made "tangible" by the prototype can be made accessible over time. This raises the issue of how to store prototypes, especially considering that teams are often spread out over different places and times. In this example, the institution and exhibition teams were located on the East Coast of the USA -in North Carolina and Washington DC respectively - while the digital design firm was on the West Coast. To make the communication as efficient as possible, they adopted a collaboration tool called Basecamp ${ }^{8}$ to save the files or video records of the prototypes.

\section{Prototypes for integrating expertise from different voices}

The following example comes from "The Emerging Issues Commons" project. The context in which it took place was the conceptual phase. In this phase the institution and external stakeholders, the exhibition

${ }^{8} \mathrm{https}$ ://basecamp.com. This type of web database is an asynchronous tool (Xu, Zhang, and Young 2008) placed at disposal of the teams for to-do lists, calendars and time tracking. It also offers the possibility to store and share any file format and to communicate through a text messaging system, which also allows users to comment on the saved files. 
design team ${ }^{9}$, and the digital media team ${ }^{10}$ were all actively involved. In the following extracts I retrace the sequence of the main steps that led to the final "Modes of Interpretation" prototype.

Senior User Experience designer, member of the digital design team: "I use a lot of the tools [prototypes] that you just mentioned, like the wireframes, information architecture, personalizing scenarios, all those things are models that we are commonly using, and to me, they are primarily just communication models, you know, they're ways for people to understand the situation or gain a common understanding of the situation of what we're designing."

Interviewer (the author): "Do you use them mainly as communication tools? Or, I mean, are they also an opportunity to think about the design?"

Senior User Experience designer: "No, they definitely serve as a way to think through the problem, you know, as we are making these exhibits, for example, North Carolina, the IEI exhibit, you know, the point of the wire frames is really to start to make our ideas, our big conceptual models, concrete, in interfaces, in whatever else. [...] So it's a way for us to move forward. Even if the model itself is very high-level, it doesn't go into the details, it's still very useful."

The senior User Experience designer is part of the digital media studio. His team, together with the exhibition team, created the Modes of Interpretation map, which is a conceptual prototype that combines four main aspects, that are: 1) the underlying narrative that was written by the IEI curators and then "translated" into a diagram by the user designers ("Meta-narrative" diagram, Figure 11); 2) the physical exhibition design, which consisted of initial sketches of the gallery plan (Figure 12) designed on the basis of the narrative by the exhibition design team, with the contribution of digital design team; 3) the visitor experience goals, as a result of the audience study (Levels of Experience, Figure 13); and 4) the digital interactive opportunities (Conceptual Map for Interactive Media, Figure 14). These documents were the outcomes of a series of activities conducted throughout intensive collaboration between all teams during the 
conceptual phase and were used to realise the Modes of Interpretation prototype. For example, one of the key models produced was the Conceptual Map for Interactive Media (Figure 14). that helped to identify digital opportunities. The Conceptual Map for Interactive Media is a framework that identifies the digital parts of the whole interactive system; that is, the digital media opportunities. For example, the "Questions" experience (Figure 15) aimed to make accessible to the visitors the statistical data that underpins all policy decisions. A "statistic visualizer" was considered to be a good opportunity to satisfy this experience goal. Only in the next design phase was this opportunity further developed and the actual 16-foot interactive wall built (Figure 16).

Even if the Conceptual Map for Interactive Media was an effective representation for articulating digital media opportunities, it was not still sufficient to define how the digital media would be integrated within the physical exhibition. Therefore, the next step was to combine the three main areas designed by the exhibition team - Introduction, Question, Collaboration areas - with the digital media configured in the Conceptual Map for Interactive Media (Figure 14). To do this, the digital media team elaborated the Experience Flowchart (Figure 17) as initial abstract visualization, combining visitor experience goals, digital media opportunities, and areas of the exhibition. All these documents produced throughout the collaboration of different teams were combined in the final prototype, called the "Model of Interpretation" (Figure 18 and 19). This conceptual prototype allowed for the organic integration of the digital media experience into the design of the gallery. The prototype supported the configuration of the gallery information space that consisted of the combination of physical space, the content, the digital media, and the visitor experience. All these elements, when well integrated, shape the way in which visitors "encounter" information that, in turn, creates the conditions in which the visitor experience happens (Frascara 2006). 


\section{Prototype to explore the problem space}

According to Dorst and Cross (2001; Dorst 2006) the creative process of design "seems more to be a matter of developing and refining together both the formulation of a problem and ideas for a solution, with constant iteration of analysis, synthesis and evaluation processes between the two notional design "spaces"” The co-evolution of problem space and solution space clearly emerges from my analysis, as prototyping contributes to defining the problem space while supporting the teams to find a solution. Prototyping is a design activity that can be seen not only as the creation of a solution - as we have just seen for the Map of Interpretation in the previous section - that could result from the combination of member's knowledge, but also as a way to exploit and combine different member's expertise in order to explore, understand, and frame the problem. In the following example coming from the Tenement Museum project, the problem space consisted in understanding whether and how the digital experience could be integrated into the exhibition. Following this extract, the designer described the importance of collaborating directly with the museum team to put together their reciprocal knowledge in order to explore and define the problem space:

Designer, principal of the digital media studio: "[...] there was a big question: "Should you start in that room or end in that room?" Like what is the sequence in which we do this, because they wanted to know how to really integrate this digital experience with essentially a tour that they know how to write, they don't want [digital experience] to be different than everything else that they do. So by sitting with them, and this is where, in the concept phase, we really talked with them about "If we put it in the beginning what does that mean, and if we put it at the end what does that mean?"

The problem was how and where to set the digital interactives in the gallery to organically integrate them within the whole experience. The designers worked closely with the curator and museum staff to create a video prototype for exploring the design space and problems, while answering this question. In this case a video scenario (Figure 20) enabled them to explore the design space.

Designer, principal of the digital media studio: "In this first concept phase, we just had the idea. Here are some stories we want to tell, we need to be able to tell many different spaces, and we like physical 
objects. So when you look at that concept video we made, it basically just has that in it. But it was enough to explain [and understand] why we need digital media in this space [...]. So that was that first, initial brainstorming session. Then, we were able to flesh that out into a real [more defined] storytelling framework."

In the example, the museum and design teams explored the problem space through the creation of a story (Erickson 1995). Scenarios and storyboards are effective prototypes for drawing a sequence of both events and experiences visitors may encounter and perform during their journey while using the digital media system. Only after having understood and defined the problem space can more refined prototypes such as "walkthroughs" allows the exploration of the high-level interactions visitors can perform during the experience.

\section{Learning by prototyping}

The education team at Cleveland Museum of Art worked collaboratively with a digital media firm for the design of all the interactives present in the Gallery One. Museum educators were instrumental in curating the space and its related experiences. Selected from a collective interview with the education teams, in this extract the director of Education and Interpretation (refers to the collaborative process with the digital design team for the design of the six interactive stations collectively known as "Lenses" (Figure 21) that allow visitors to discover information about related artworks placed adjacently.

Director of the Education and Interpretation team: "[...] Our team were collaborating with [the external designer] all the time but we were making the decisions what [collection] objects are going in and what are themes of the projects and we are giving this to Local Projects."

Being actively engaged in the collaboration with the digital team, the education team was able to "learn by doing"; they were acquiring new knowledge about the digital design, consisting, for example, in the relationships between interface components, layout and information structure, and a general understanding of how visitors would have interacted with the content. The museum team internalised knowledge by 
actively collaborating with the digital design team:

Director of the Education and Interpretation team: "One of the first groupings we came up with was the Lion grouping. That was a beginning and then from that we created different vignettes. Again, it would be an interactive grouping and we would hand it over to Local Projects and they would come in and come up with an idea for a media design or game to relate to that theme. And then we would talk back and forth, how it will work, should it be different? It was very collaborative. [Then] we would create content in the form of spreadsheets and then we would give them to Local Projects with assets and different information."

The knowledge acquired and internalized by the education and interpretation team members was vital in producing spreadsheets and assets in which they wrote digital content describing the objects selected. All this information was then (re) combined with the wireframe and mock-up prototypes in order to advance the design of the interactive.

\section{Prototyping stimulates conversation amongst team members}

Prototypes facilitate conversation amongst members of the team. In the interview I conducted with Dana Mitroff Silvers emerged the benefit of using prototypes even in the very early phases of a project to stimulate conversation between museum members and encourage feedback in order to test early ideas. She describes the advantage of using a low fidelity approach for a project at the Getty Center ${ }^{11}$ :

"It turned out that all the senior staff members and curators who were user testers completely understood the prototypes and were able to give the team feedback. A couple of more conservative staff members needed some gentle encouragement, but even in a test with high-level staff, including a vice president and a director, they understood that the purpose was to test a concept. No one had a problem with looking at a paper prototype.”(Mitroff Silvers et al. 2014) Angeles . 
According to Erickson (1995) prototypes are "design artefacts [which] play a role in catalysing communication among the various audiences involved in the design process." Using prototypes as a tool to receive feedback from stakeholders is more effective than having them just read a document that describes the concept. This makes a low fidelity prototype an effective tool for communicating the design and creating an accepted set of references and a common agreement amongst museum, design, and development team members. This is particularly important in the early phase in order to consolidate the main concept between museum and design teams (and possible external stakeholders), avoiding significant changes in more advanced steps of the process (Walker et al. 2002).

However, the feedback is important in any phase of the process. Another example suggests that the design team might look for different kinds of feedback according to the state of the design. In other words, it is important to choose a proper type of prototype to get useful feedback in order to advance the state of the design and development. In the following example, to design a very large multi-touch screen (Figure 22) for Gallery One at the CMA, the teams faced particularly complex challenges, especially in terms of information structure and visitor interaction. The museum and digital team made extensive use of prototypes to test solutions internally and with museum team to solve the complex problem of high numbers of interactions. The design team initially produced several concepts, testing them with sketchy prototypes and wireframes together with the museum team (Figure 23). But at a certain point these low fidelity prototypes did not produce any more improvement, and the team got stuck, as the principal of one of the digital design firms said ${ }^{12}$ :

12 I am grateful to Jake Barton who recommended his video presentation at the Eyeo Festival 2013 which describes how his design team made use of prototypes to design the Collection Wall at Gallery One. The two extracts from the presentation can be found at: https://vimeo.com/73379787 
“[...] we couldn't get our way out of concept and out of wireframe and we couldn't get ourselves to a point where we could pull the trigger, but in fact I finally just said forget it let's just pick one, let's just start making."

As a consequence the design team started creating high fidelity prototypes (Figure 24) to test the information architecture of the system and the complex interactions it permitted. This approach turned out to be particularly productive for the team since:

Principal of the external design firm: "[...] this prototype was right in front of us, in full scale. We could suddenly imagine all the main ways to solve issues. So, this is [...] the idea of these individual zones which we called irises; that came through loud and clear. The individual carousels were really working. The way in which the individual irises could map, one to the next. And that if you chose an individual tile in between them it would just move to the closest iris. All of these things that now feel very very intuitive really revealed themselves here. And it was because it was full scale and we were all gathered together. We could finally just hash out exactly what was going to really happen. Rather than to project ourselves into what we imagined was going to happen.'

Prototypes were welcomed by all stakeholders, since they represented the moment at which they could really understand the design. In this last example, the high fidelity prototype allowed museum staff to understand the design they had seen evolving through concepts, experience frameworks, content structures, and the wireframe of the interface. Thanks to their high degree of both aesthetic fidelity and functionality, high fidelity prototypes provide a real visitor experience, which is useful in order to receive specific feedback from stakeholders and visitors before implementing the final digital system.

\section{Discussion}

The findings from this study showed that prototypes can make a significant contribution to the knowledge management process in the design of digital media for museums. The first theme describes the role of prototypes to represent how the design "is going to work." They are tangible instantiations of design ideas (Coughlan 2007) created before the final digital media exist (Houde and Hill 1997). Despite the type 
of prototype used, the most effective is one "that, in the simplest and most efficient way, makes the possibilities and limitations of a design idea visible" (Lim et al. 2008). Being tangible and visible results in a clearer way of communicating ideas within teams, and facilitating collaboration amongst team members (Johansson and Arvola 2011). This is particularly important in the early phase, when the collaboration between all members is more intense, aiming to consolidate the main concept between all stakeholders, and to avoid significant changes in more advanced steps of the process (Walker et al. 2002).

Prototypes can also promote knowledge transfer. According to Müller and Thoring (2011), prototypes are design artifacts that can facilitate communication between members of different teams, since they promote knowledge exchange. Rhinow, Köppen, and Meinel (2012) emphasise the relevance of prototypes as "boundary objects" between team members who belong to different areas of expertise. In their study, Star and Griesemer (1989) define boundary objects as "both adaptable to different viewpoints and robust enough to maintain identity across them.”

As representations of ideas and media for knowledge exchange prototypes that happen at specific points of the project can also be used in later phases of a project. The findings show that it is important to store knowledge produced and place it at the disposal of team members throughout the entire project. Prototypes have the capacity to retain knowledge and make it "accessible" anytime and anywhere to support collaborative work exchange (Muller and Thoring 2011). This raises the issue of how to store prototypes, especially considering that often teams are spread out in different places and times.

Prototypes work as representations of, vehicles for transferring, and ways of storing, knowledge. By applying the theoretical lenses of the SECI model to the study, it is interesting to note that the three categories - representing, transferring, and storing - squarely fall within the "externalization" mode. As Nonaka (Nonaka, Konno, and Toyama 2001) describes: “through externalization, the process of articulating 
tacit knowledge into explicit knowledge, knowledge becomes crystallized, thus able to be shared by others, and becomes the basis of new knowledge."

Prototypes go further than merely externalising knowledge. They contribute to the process of combining expertise coming from different design team members. By building prototypes, the teams go beyond talking and thinking about a problem as they actually make progress through action (Coughlan 2007). As emerged in the findings, prototyping is a process integrating members' knowledge that supports both the exploration of the problem space and the definition of a solution. This creative process sees problems and solutions evolve together through iterative cycles of analysis-synthesis-evaluation. In their seminal study, Dorst and Cross (2001) demonstrate that the problem-solving aspect of design could be described as a "co-evolution of problem and solution spaces." According to the authors:

\footnotetext{
"It seems that creative design is not a matter of first fixing the problem and then searching for a satisfactory solution concept. Creative design seems more to be a matter of developing and refining together both the formulation of a problem and ideas for a solution, with constant iteration of analysis, synthesis and evaluation processes between the two notional design 'spaces' - problem space and solution space." (Dorst and Cross 2001)
}

The analysis essentially consists in the understanding (and not defining) of the problem; the synthesis reflects on the problem by generating and finding ideas for a solution; evaluation tests the idea for a solution. In such "co-evolutionary" and iterative design processes, where problems and solution evolve together, prototyping plays a fundamental role in deepening the understanding of a solution throughout any iteration. Prototyping allows for the evaluation of a possible solution and then the integration of team members reflections, expertise, and feedback for the creation of a new prototype, advancing the design toward a final solution.

According to Nonaka (2003) explicit knowledge "has to be actualized through action, practice, and reflection so that it can really become knowledge of one's own." This is exactly what happened in the 
Gallery One example. Prototyping played an important role in facilitating the collaboration between museum and digital design teams; by interacting with the prototype, the museum team members embodied new knowledge (e.g. about the interface functions, information structure, and interactions) which then was able to create content that best fit the interactive experience. In the SECI model this process corresponds to “internalization.” The knowledge any member internalizes becomes the base, together with knowledge they already possess, for a new iteration of design, thereby advancing the design toward the final solution. Paraphrasing Nonaka (2001) internalized knowledge acquired by experiencing the prototype is (re) applied “to broaden, extend, and reframe members' tacit knowledge".

The prototype facilitates the process of engaging different members in a dialogue of knowledge exchange. Nonaka describes this process with the term socialization: "tacit knowledge accumulated at the individual level is in turn shared with others through socialization" (Nonaka 2001). For example, a designer could help a curator experience a wireframe model, thereby stimulating them to reflect and give feedback. Nonaka writes, "The key to acquiring tacit knowledge is experience. Without some form of shared experience, it is extremely difficult for one person to project her- or himself into another individual's thinking process." For example, a wireframe can create the specific context constituted by interface structure and interactions (this is the context of the design team). In this case, the curator can also participate in the design context and, by experiencing it through a prototype, can experience the design knowledge, which would have been difficult to understand through verbal explanations given by the designer. This process stimulates conversation, which is fundamental for advancing the design, as prototypes allow "stakeholders to experience the design and to give feedback" (Muller Thoring 2011). 


\section{Conclusion}

This study explored the role of prototyping in supporting the transmission and combination of knowledge across team members by integrating different forms of expertise, from curatorial to design to technical domains.

The capacity of prototypes to make design ideas tangible promotes knowledge transfer. The fruitful exchange of knowledge turns out to be a crucial in collaborative design practice throughout the entire design project; knowledge coming from curatorial, education, audience development and digital teams is what informs the design. But prototypes go further than just being a vehicle for transferring knowledge, as they support the combination of different forms of expertise; this is what forms the design.

Knowledge does not only move from an individual to the entire team, but also the other way round: that is, knowledge externalized by a prototype can be embodied by a member of the team and, in turn, be the base for new knowledge for further iterations of a design. Finally, prototypes can promote "socialization" since they facilitate the process of engaging different individuals in a dialogue of knowledge exchange.

If we assume that the final design solution should be the "best compromise" resulting from a creative process where multiple voices with various backgrounds and their own expertise take part, then the knowledge exchanged in this process becomes significant for the final design. For this reason, studying knowledge management in digital media design practices for museums can contribute to better understandings of how and why team members can take advantage of prototypes to create, transfer, combine, and embody knowledge. 


\section{Further Research}

Knowledge creation is a continuous and dynamic process in which knowledge is built through perpetual interactions between the modes of conversions "in the spiral knowledge creation" (Nonaka 2000, 2001). In this paper I focused on different modes of knowledge conversion singularly outlining some possible interactions between the four modes in the spiral of knowledge creation. Further research focused on how and whether prototyping contributes to the dynamic evolution of knowledge throughout the four SECI modes would form an interesting complement to my study.

It would also be of interest to further investigate prototyping practices in digital media design for museums through other perspectives of knowledge management theory. The SECI model is just one part of the theory of knowledge creation conceived by Nonaka. The concept of "Ba" is another crucial and fascinating theoretical aspect to refer to in further research. Ba can be considered as a conceptual space underlying knowledge creation. Nonaka and Konno $(1998,2001,2005)$ define Ba in knowledge creation as a platform where knowledge is created, shared, and exploited. The core characteristic of this "space" is the interaction among individuals (e.g. team members) and with the environment (e.g. the space where design activities happen) occurring in a specific time - since Ba takes into consideration also the time when such interactions take place. It is not necessarily only a physical space (e.g. a design firm media lab) but also virtual (e.g. a collaborative virtual environment on the Internet) and mental (e.g. a shared experience facilitated by a prototype), or any combination of these three spaces. As a result, the concept of Ba denotes a specific "time and space" (Nonaka 2001). As the staring point of a possible future strand of research, I would suggest considering how and whether prototypes can facilitate successful knowledge creation in different types of $\mathrm{Ba}$ when designing digital media for heritage. 


\section{References}

Alexander, Jane, Barton, Jake and Goeser, Caroline. 2013. "Transforming the Art Museum Experience: Gallery One”, in Museums and the Web 2013, N. Proctor \& R. Cherry (eds). Silver Spring, MD: Museums and the Web.

Bazeley, Patricia, and Kristi Jackson. 2013. Qualitative data analysis with NVivo. Sage Publications Limited.

Birks, Melanie, Ysanne Chapman, and Karen Francis. 2008. "Memoing in qualitative research probing data and processes." Journal of Research in Nursing, vol. 13, no.1, pp. 68-75.

Bucciarelli, Louis L. 1994. Designing engineers. MIT press.

Calvillo, Nerea, Alberto Corsín Jiménez, Hernani Dias, Lina Dib, Estalella, Adolfo, García, Marcos, Guggenheim, Michael, Leach, James, Lezaún, Javier, and Marcus, George. 2010. "PROTOTYPING PROTOTYPING." Episode 2. Pdf file:

https://www.researchgate.net/profile/Alberto_Jimenez5/publication/267509851_Prototyping_prototy ping/links/54512d0c0cf24884d886fb54.pdf

Charmaz, Kathy. 2006. Constructing Grounded Theory: A Practical Guide through Qualitative Analysis. SAGE Publications Ltd.

Coughlan, Peter, Fulton Suri, Jane, and Canales, Katherine. 2007. "Prototypes as (Design) Tools for Behavioral and Organizational Change A Design-Based Approach to Help Organizations Change Work Behaviors." The journal of applied behavioral science 43, no. 1, pp. 122-134.

Dorst, Kees. 2006. Understanding Design, Revised Edition. Amsterdam; Enfield: BIS Publishers.

Dorst, Kees, and Nigel Cross. 2001. "Creativity in the design process: co-evolution of problem-solution." Design Studies, vol. 22, no. 5, pp. 425-437, Sep.

Dubberly, Hugh and Evenson, Shelley. 2011. "Design as learning - or knowledge creation - the SECI model." Interactions 18 , no. 1, pp. 75-79.

Dunne, Ciarán. 2011. "The place of the literature review in grounded theory research." International Journal of Social Research Methodology 14, no. 2, pp. 111-124.

Erickson, Thomas. 1995. "Notes on design practice: stories and prototypes as catalysts for communication", in Scenario-Based Design, edited by John M. Carroll, 37-58. NY, USA: John Wiley \& Sons.

Farrell, Robert, and Cliff Hooker. 2013. "Design, science and wicked problems." Design Studies, vol. 34, no. 6, pp. 681-705, Nov. 
Frascara, Jorge. 2006. Designing Effective Communications: Creating Contexts for Clarity and Meaning. New York: Allworth Press.

Gerber, Elizabeth, and Carroll, Maureen. 2012. "The psychological experience of prototyping." Design studies 33, no. 1, pp. 64-84.

Glaser, Barney G. and Strauss, L. Anselm. 2009. The discovery of grounded theory: Strategies for qualitative research, $6^{\text {th }}$ Ed. Transaction Publishers.

Houde, Stephanie, and Hill, Charles. 1997. "What do prototypes prototype." Handbook of human-computer interaction 2,pp. 367-381.

Jagodzinski, P., Reid, F. J. M., Culverhouse, P.,Parsons, R., and Phillips, I. 2000. "A study of electronics engineering design teams." Design Studies 21, no. 4, pp. 375-402.

Johansson, Maria, and Mattias Arvola. 2007. "A Case Study of How User Interface Sketches, Scenarios and Computer Prototypes Structure Stakeholder Meetings." In Proceedings of the 21st British HCI Group Annual Conference on People and Computers: HCI... but Not as We Know It-Volume 1, Swinton, UK, pp. 177-84.

Manker, Jon, and Arvola, Mattias. 2011. "Prototyping in game design: Externalization and internalization of game ideas." In Proceedings of the 25th BCS Conference on Human-Computer Interaction, pp. 279288. British Computer Society.

Kvale, Steinar. 2008. Doing interviews. Sage.

Le Dantec, Christopher A., and Yi-Luen Do, Ellen. 2009. "The mechanisms of value transfer in design meetings." Design Studies 30, no. 2. Pp.119-137.

Lee, Kim, and Cassidy, Thomas. 2007. "Principles of design leadership for industrial design teams in Taiwan." Design Studies 28, no. 4, pp. 437-462.

Lim, Youn-Kyung, Erik Stolterman, and Josh Tenenberg. 2008. "The anatomy of prototypes: Prototypes as filters, prototypes as manifestations of design ideas." ACM Transactions on Computer-Human Interaction (TOCHI). Volume 15, no. $2,7$.

Mason, Marco. 2013. "DiMe4Heritage: Design Research for Museum Digital Media," in Museums and the Web 2013, N. Proctor \& R. Cherry (eds). Silver Spring, MD: Museums and the Web.

Mitroff Silvers, Dana, Emily Lytle-Painter, Ahree Lee, Jack Ludden, Ben Hamley and Yen Trinh. 2014. "From Post-its to Processes: Using Prototypes to Find Solutions." in Museums and the Web 2014, Proctor, Nancy and Cherry, Richard (eds). Silver Spring, MD: Museums and the Web.

McCurdy, Michael, Christopher Connors, Guy Pyrzak, Bob Kanefsky, and Alonso Vera. 2006. "Breaking the Fidelity Barrier: An Examination of Our Current Characterization of Prototypes and an Example 
of a Mixed-Fidelity Success." In Proceedings of the SIGCHI Conference on Human Factors in Computing Systems, 1233-42. CHI ’06. NY, USA: ACM.

McLean, Kathleen. 2011. “Whose Questions, Whose Conversations?”, in Letting Go? Sharing Historical Authority in a User-Generated World, Adair, Bill, Benjamin Filene, and Laura Koloski, eds. Philadelphia: Pew Center for Arts \& Heritage, pp. 70-77.

McLean, Laird D. 2004. "A review and critique of Nonaka and Takeuchi's theory of organizational knowledge creation." In 5th UFHED/AHRD Conference.

Müller, Roland M., and Thoring, Katja. 2011. "Understanding Artifact Knowledge in Design Science: Prototypes and Products as Knowledge Repositories." In AMCIS.

Nonaka, Ikujiro. 1994. "A dynamic theory of organizational knowledge creation." Organization science 5, no. 1, pp.14-37.

Nonaka, Ikujiro and Takeuchi, Hirotaka. 1995.The knowledge-creating company: How Japanese companies create the dynamics of innovation. Oxford university press.

Nonaka, Ikujiro and Toyama, Ryoko. 2003. "The knowledge-creating theory revisited: knowledge creation as a synthesizing process. "Knowledge management research \& practice 1, no. 1, pp. 2-10.

Nonaka, Ikujiro, Toyama, Ryoko and Konno, Noboru. 2000. "SECI, Ba and leadership: a unified model of dynamic knowledge creation." Long range planning 33.1, pp. 5-34.

Nonaka, Ikujiro, Konno, Noboru and Toyama, Ryoko. 2001. "Emergence of "Ba. Knowledge emergence: Social, technical, and evolutionary dimensions of knowledge creation, 1, pp. 13-29.

Nonaka, Ikujiro and Konno, Noboru. 2005. "The concept of "Ba": building a foundation for knowledge creation." Knowledge management: critical perspectives on business and management 2, no. 3, pp. 53.

Nonaka, Ikujiro and Konno, Noboru. 1998. "The concept of "Ba': Building foundation for Knowledge Creation. California Management Review", Vol 40, No.3 Spring.

Patton, Michael Quinn. 1990. Qualitative evaluation and research methods . SAGE Publications, inc. Petrie, Jennifer N., and Kevin A. Schneider. 2007. "Mixed-Fidelity Prototyping of User Interfaces", in Interactive Systems. Design, Specification, and Verification, Gavin Doherty and Ann Blandford, (Eds), pp. 199-212. Lecture Notes in Computer Science 4323. Springer Berlin Heidelberg. Polanyi, Michael. 1967. "The tacit dimension." The University of Chicago press.

Punch, Keith F. 2013. Introduction to social research: Quantitative and qualitative approaches. Sage. 
Rhinow, Holger, Köppen, Eva and Meinel, Christoph. 2012. "Prototypes as boundary objects in innovation processes." In Proceedings of the 2012 International Conference on Design Research Society, Bangkok, Thailand.

Rogers, Yvonne, Helen Sharp, and Jenny Preece. 2015. Interaction Design: Beyond Human-Computer Interaction. John Wiley \& Sons.

Rudd, Jim, Ken Stern, and Scott Isensee. 1996. “Low vs. High-Fidelity Prototyping Debate.” Interactions 3, no. 1, pp. 76-85, Jan.

Star, Susan Leigh and Griesemer, James R. 1989. "Institutional ecology,translations' and boundary objects: Amateurs and professionals in Berkeley's Museum of Vertebrate Zoology, 1907-39." Social studies of science 19 , no. 3, pp. 387-420.

UPM, Press Relase, 20144

Virzi, Robert A., Sokolov, Jeffrey L. and Karis, Demetrios. 1996. "Usability problem identification using both low-and high-fidelity prototypes." In Proceedings of the SIGCHI Conference on Human Factors in Computing Systems, pp. 236-243. ACM.

Walker, Miriam, Leila Takayama, and James A. Landay. 2002. "High-Fidelity or Low-Fidelity, Paper or Computer? Choosing Attributes When Testing Web Prototypes." Proceedings of the Human Factors and Ergonomics Society Annual Meeting 46, no. 5, pp. 661-665, Sept.

Warfel, Todd Zaki. 2009. Prototyping: A Practitioner's Guide. Brooklyn, N.Y.: Rosenfeld Media. Wilkie, Alex. 2010. Prototypes in design: materializing futures. In: Christopher Kelty, Alberto Corsin Jimenez and George E. Marcus, eds. Protoyping Prototyping. Madrid: ARC Studio, pp. 43-50.

Xu, J., Zhang, J.,Harvey, T. and Young, J. 2008. "A survey of asynchronous collaboration tools." Information Technology Journal 7, no. 8, pp. 1182-1187.

\section{Acknowledgments}

The Marie Curie research project (started October 2012) is funded by the European Union - Marie Curie Actions International Outgoing Fellowships for Career Development (IOFs). The outgoing stage of the fellowship (2013-14) took place at the Massachusetts Institute of Technology supervised by Prof. John Durant from the Science, Technology and Society Program; and the return stage (2015) takes place at the University of Leicester supervised by Dr. Giasemi Vavoula from the School of Museum Studies. 
I am grateful to the Principal Investigator Dr Giasemi Vavoula for the support she has given, and con- tinues to give me, with this research project.

I would also like to express my gratitude to the museum practitioners and designers who afforded me their time for interview, providing helpful information and documents. For this article, I would like to thank in particular: Wendy Burkland, Melinda Walker, and Anita Brown-Graham (The Institute of Emerging Issues) for their generous availability and interest in my project; David Waingarten and Brad Johnson (Second Story Interactive Studios) for the great support in organizing interviews with the design team (Chris Dewan, Daniel Meyers, David Brewer, Thomas Wester, Michael Godfrey, Sorob Louie, Jennifer Dolan, Kirsten Southwell, Norman Lau, Alex Cho, Marc Lehman, Jinu Yang, Swanny Mouton, Sam Jeibmann, Philippe Laulheret, Matthew Fargo, Donald Richardson); Gallagher \& Associ- ated (Cybelle Jones and Sujit Tolat); Barbara Martin (Museum fine Art in Boston) for her great support in organizing interviews with the museum practitioners and design firms; MFA museum team: Barbara Martin, Jenna Fleming, Lynn Courtney, Elliot Davis, and Erica Hirshler; Design firms: RLMG (Richard Lewis, Stephanie Stewart, and Diana Bonfilio), Small Design (David Small and Jenna Fizel), and The 47th (Ann Karash Kimura); Jake Barton, principal of Local Projects, and Jane Alexander from the Cleveland Museum of Art for her fundamental support in organizing interviews with the museum practitioners; Gallery One team: Jane Alexander, Caroline Goeser, Seema Rao, Jennifer Foley Meghan Stockdale, Elizabeth Bolander, Andrea Bour, Niki Krause, Mary Suzor, and Thomas Barnard; Josh Goldblum, principal of BlueCadet Design, and Kate Quinn from the Penn Museum for their fundamental support in organizing interviews; Museum team: Yuan Yao, Lucy Fowler Wil- liams, Allison Francies, Kevin Schott, Courtney O’Brien, and Jenn Reifsteck; BlueCadet design team: Troy Lachance, Aaron Miller, Kim Quinn, Mark Llobrera, Stacey Martens, Aaron Richardson, Victoria Jones, and Paul Rudolph; Annie Polland and Nick Capodice at the Tenement Museum NYC; Potion Design Studio: Philip Tiongson (principal), Abby Palmer, and Jonathan Bobrow; and Dana Mitroff Silvers for the stimulating conversations on design issues. 
I am grateful to Dr Catharina Hendrick and Dr Ryan Nutting from the School of Museum Studies who have supported and intellectually stimulated me during the writing of this article. 